\title{
The Difference Factors Influencing the Chinese and Foreign Creative Fashion Design Talent Cultivation and Contrast Analysis
}

\author{
Yating Zhang, Hongjian Qu \\ Clothing Institute, Shanghai university of Engineering and Technology, Shanghai, China
}

Email address:

2974315226@qq.com (Zhang Yating ), quhongjian0451@126.com (Qu Hongjian)

To cite this article:

Zhang Yating, Qu Hongjian. The Difference Factors Influencing the Chinese and Foreign Creative Fashion Design Talent Cultivation and Contrast Analysis. International Journal of Literature and Arts. Vol. 3, No. 4, 2015, pp. 66-70. doi: 10.11648/j.ijla.20150304.16

\begin{abstract}
This paper summarizes 11 possible difference factors affecting domestic and foreign creative fashion design talent training through an extensive literature review, and extracts three common factors by the R-type factor analysis. Finally, picking up the University of Edinburgh with first-class School of Design and the domestic Donghua University with excellent clothing major for example, and providing improvement direction for Chinese creative costume design talent training.
\end{abstract}

Keywords: The Chinese and Foreign Creative Fashion Design, Talent Cultivation, Different Factors, Comparative Analysis

\section{Introduction}

With the rapid development of economy and technology, as well as the deepening of economic globalization, the creative industries have been the core of the industry's economic growth and the important factors of measuring international competitiveness. As part of the creative industries, the development of creative fashion design lies in the promotion of talents. Currently, the international influence of our clothing brands isn't high,and brand imitation seriously, especially children's wear. Moreover, the training model of excellent designers is single , and teaching exists some errors, also irrational structure of teachers and single teaching methods and other malpractices. With the advent of the personalized era, clothing consumer brand awareness has enhanced, and increasingly demanding for all aspects of clothing. In the face of strong international brands attack, China want to complete the shift of"big clothing country" to "powerful clothing country" , which needs a batch of professional creative fashion design talents to build counter market, and win high efficiency. From the literature consulted, which are mostly from the status of fashion design talents to explore teaching strategies. This paper, from international perspective,analyzes the difference factors affecting Chinese and foreign creative fashion design talent training, providing improved direction for Chinese creative fashion design talent training.

\section{Different Factors Influencing the Chinese and Foreign Creative Fashion Design Talent Cultivation}

Different countries would have a different innovative talent training model due to a variety of difference factors such as political system, cultural background, economic and science and technology, religion, etc. Some foreign universities have world-class costume design talent training mode, for example, the University of Edinburgh, the University of the Arts London and London College of Fashion (LCF) and the New York Fashion Institute of Technology (FIT), these stylish top educational institutions with advanced and successful educational philosophy and educational model which is worth learning for the domestic colleges and universities lack of creative fashion design talent cultivation experience. Therefore, this article mainly on account of higher education, through accessing to the relevant literature and from the concept of education and culture, their conditions teachers and students, the way of university-industry-research cooperation, the education system etc, summarizes 11 possible difference factors affecting domestic and foreign creative costume design talents training, as shown in Table1: 
Table 1. difference factors affecting domestic and foreign creative costume design talents training.

\section{Factor and importance}

Educational idea

Direction indicator of talent training standard,and reflecting the goal of education.

\section{Educational culture}

Presenting the essence of higher educational institutions, and inspiring teachers and students in the spirit .

\section{Teaching management}

It not only plays a role of constraints in the layers of university personnel, but also to promote the smooth progress of the various teaching.

\section{Academic evaluation}

It reflects the quality of teaching achievements, as well as the comprehensive ability level of talent, promoting the continuous improvement.

Students themselves

Sources of students of higher education, are numerous students trained by early education, primary education and secondary education.Higher education selects personnel to train, which can improve the efficiency of personnel training.

Faculty

An important fact of talents training, and determining the implementation of talent personnel training programs and the quality of talent outputs .

\section{Curriculum provision}

source of students gaining the knowledge, rich curriculum to expand students' knowledge, and to provide a theoretical basis for a variety of innovations.

Teaching method

Having a major impact on students' learning patterns and thought patterns, and determining the efficiency of teaching.

\section{University-industry-research cooperation}

Universities, enterprises, and the project parties to work closely not only strengthens the exchange information, but enhances students' practical ability and creative thinking skills.

\section{Educational system}

education system of a country is the basis for the formation of the educational model.

Education funding

Providing economic base for the personnel training. It is an important educational incentives,and help to stimulate innovation of the entire education system.

\section{the overall difference of domestic and foreign}

Foreign universities emphasize the development of first-class designers, such as UK University of Edinburgh. Domestic teaching objectives are unclear.

Foreign more emphasis on independent innovation.Like Yale's good speculation. Domestic more emphasis on the doctrine of Harmonious Thought of Confucianism. Such as Tsinghua's motto is self-improvement, social commitment.

Foreign more tend to establish boards and councils.

Domestic mainly carrying out bureaucratic.

Foreign more emphasizing on practical ability,which closes to the society. Domestic using of the credit system, and the final exam is dominant,which is easy to be divorced from the society for students.

The difference of Chinese and foreign basic education and family education mode has an important influence on the starting to receive higher education. such United States, elementary education with a wide range of courses, and middle school students begin to freely select courses interesting. Domestic students' elective liberty has been restricted,more familial interference .

Foreign more emphasizing on teachers with experience working in corporations and part-time jobs in enterprises .

Domestic outstanding teachers are often far from the forefront of teaching, and teachers are only the teacher's identity.

There are numerous selective courses aboard,which appeal to students to learn and to learn to bring forth new ideas.

Domestic students tend to have a small choice free.

Abroad using interactive, heuristic teaching methods to improve students' creative thinking and practical ability. Domestic teachers to rely on teaching outline and textbooks, lack of cultivation of students' innovative thinking ability.

Foreign Cooperation is a must, and a commonality.

Domestic research and teaching are a little separation and not wide enough to cooperate with enterprises, still scientific research results into inadequate.

Foreign government adopted the policy of non-interference.Domestic more emphasis on implementation of the government education system for colleges and universities.

Foreign funding of higher education mainly has consultations, input and output funding allocations, such as the US formula funding model, the British fund system mode.Later,introducing performance funding mechanism.Domestic financial allocation for higher education is the "basic expenditure budget plus project expenditure budget". Financial supports lack of pertinence, unbalanced development of higher education. 


\section{Analysis of the Difference Factors Influencing the Chinese and Foreign Creative Fashion Design Talent Cultivation}

\subsection{Data Collection}

The investigation mainly thinks of clothing professionally related and bachelor degree or above students, teachers and students having a foreign class and foreign students as the research objects.120 questionnaires are handed out, excluding invalid questionnaires, and 98 valid questionnaires. Its recovery rate reaches $81.7 \%$. Software processing data is SPSS17.0.

\subsection{Difference Factor Analysis Chinese and Foreign Creative Fashion Design Talents Cultivation}

\subsubsection{Reliability Analysis}

Conduct reliability test of Scale of different factors affecting domestic and foreign creative fashion design talent cultivation to ensure the correctness of the contents of the questionnaire survey and reliability of analysis of the results. Cronbach's reliability coefficient of reliability analysis $\alpha=0.834$. According to the letter of the standard determination, internal reliability of the scale is acceptable, and $\mathrm{KMO}=0.843$. KMO value and reliability coefficient indicate survey data suitable for factor analysis.

\subsubsection{Factor Analysis}

\section{(i). Reducing Dimensionality and Extracting Common \\ Factors}

Through "analysis - Dimension Reduction - factor analysis" of SPSS software, based on the method of eigenvalues greater than 1 decimation factor to extract common factors ,the results obtained in the following figure 2 , which shows that the first three principal components of eigenvalues greater than 1 , and the contribution rate of cumulative variance reaching $62.27 \%$. Extracting these three common factors can explain most of the information in the original variables, so to select the first three principal components to analyze.

Table 2. eigenvalues and variance contribution table(Total variance of interpretation).

\begin{tabular}{lllll}
\hline \multirow{2}{*}{ Element } & \multicolumn{2}{l}{ Initial eigenvalue } & & \multicolumn{2}{c}{ Extraction of squares and loading } \\
\cline { 2 - 5 } & Total & Variance \% & accumulation \% & Variance \% \\
\hline 1 & 4.343 & 39.478 & 39.478 & 4.343 \\
2 & 1.342 & 12.203 & 51.681 & 1.342 \\
3 & 1.165 & 10.588 & 62.27 & 1.165 \\
4 & 0.847 & 7.702 & 69.971 & 12.203 \\
5 & 0.663 & 6.026 & 75.997 & \\
6 & 0.581 & 5.282 & 81.28 & \\
7 & 0.536 & 4.874 & 86.154 & \\
8 & 0.458 & 4.164 & 90.318 & \\
9 & 0.439 & 3.988 & 94.306 & \\
10 & 0.353 & 3.21 & 97.515 & \\
11 & 0.273 & 2.485 & 100 & \\
\hline
\end{tabular}

\section{(ii). Nomenclature for Common Factors}

$\mathrm{x} 1$ and $\mathrm{x} 2$ reflect the concept of education and culture have impact on differences of Chinese and foreign creative fashion design talent cultivation; $x 5$ reflects the impact of the student's own conditions for personnel training output and other factors reflecting the internal resources of universities and government investment in higher education. Therefore, three common factors were named: Higher education resources, education and cultural ideas, students themselves.

Table 3 is the rotated factor loading matrix based on "maximum variance method", which indicates that has extracted three common factors from 11 difference factors influencing Chinese and foreign creative fashion design talent, and shows the different factors of loading case: factor 1 has a large load on $\mathrm{x} 3, \mathrm{x} 4, \mathrm{x} 6, \mathrm{x} 7, \mathrm{x} 8, \mathrm{x} 9, \mathrm{x} 10, \mathrm{x} 11$, the factor 2 has greater load on $\mathrm{x} 1, \mathrm{x} 2$, a greater load of factor 3 on $\mathrm{x} 5$.

Table 3. rotated factor loading matrix.

\begin{tabular}{llll}
\hline & component & & $\mathbf{3}$ \\
\hline & $\mathbf{1}$ & $\mathbf{2}$ & 0.016 \\
X1: Educational idea & 0.106 & 0.836 & 0.024 \\
X2: Educational culture & 0.154 & 0.848 & -0.639 \\
X3: Teaching management & 0.519 & 0.027 & -0.168 \\
X4: Academic evaluation & 0.573 & 0.316 & 0.747 \\
X5: Students themselves & 0.309 & 0.024 & 0.327 \\
X6: Faculty & 0.766 & 0.185 & 0.092 \\
X7: Curriculum provision & 0.776 & 0.11 & -0.1 \\
X8: Teaching methods & 0.675 & 0.252 & -0.052 \\
X9: university-industry cooperation & 0.737 & -0.051 & -0.036 \\
X10: Educational system & 0.646 & 0.357 & 0.25 \\
X11: Education funding & 0.752 & 0.054 & \\
\hline
\end{tabular}




\section{Comparative Analysis of Chinese and Foreign Creative Fashion Design Talent Cultivation}

Based on Edinburgh University and Donghua University

Based on the difference factors affecting domestic and foreign creative costume design personnel, this article focusing on higher education resources, education and cultural ideas and students themselves,sums up the creative talents training characteristics of Art and fashion design major of the University of Edinburgh and art and fashion design major of Donghua University and makes comparative analysis, as shown in Table 4:

Table 4. Edinburgh University and Donghua University respective characteristics of creative fashion design talents training.

The main characteristics of creative fashion design talents cultivation
of University of Edinburgh
Educational idea
Training future fashion innovators
They are committed to developing students' personal creative freedom
and innovative design concept. Teachers and students are in close contact
and common development. To ensure students career development
opportunities. Its educational and cultural core emphasizes on social
responsibility and intelligent design, focusing on training emotional
design thinking, and design skills responding to different demands of
consumer.
Curriculum provision
Basically covering all segments of today's fashion
Curriculum includes fashion design, brand management, visual
marketing, marketing, fashion media, digital, fashion photography, shoes,
jewelry design and so on. The school is one of the world's most
comprehensive fashion specialization education institutions. In addition,
the College encourages interdisciplinary collaboration.
Faculty
Designer of enjoying international renown
Teachers with highly creative and high academic standards. For example,
Mal Burkinshaw graduated from Edinburgh College of Art,and got a first-
class degree in women's fashion. He won Master's degree in the Royal
College of Art. After graduation working in Italy Benetton as a full color
designer, then as a freelance designer. In addition to his role as project
director of Edinburgh College of Art Fashion, currently at the London
College of Fashion and the Berlin International University of Art and
Design,he has also served as an external examiner.
university-industry cooperation
Overseas Education Liaison

College developed a lively international program of activities which reflects the tutors active research and cooperation with universities, organizations worldwide to promote students' continuous efforts to forge ahead. Constantly to update curriculum, and according to the fashion industry regularly to update the project and keep the simultaneous development of apparel manufacturing.

Teaching methods

\section{Studio System}

The college is to start teaching through the studio system, promoting a high frequency between instructors and students, and the students get a lot of attention. Students have their own studio, which is equipped with its excellent learning facilities

Teaching management

\section{Set up various organizations}

There are many organizations and committees,to their own duties, and contact with each other, such as: The University Court, the review committee (or Academic Committee), the General Council, the College Board.
The main characteristics of creative fashion design talents cultivation of Donghua University of China

Developing international high-quality talents and high-level of achievements

College adheres to Characteristic development road of Donghua, implementing engineering and arts crossing, and all-round development, to build a leading, internationally renowned specialty education system, and to cultivate an international perspective talent of Mainland.

relatively rich

Fashion College curriculum includes apparel painting techniques, basic body, interior textile design topics, introduction to design, fashion art foundation, apparel marketing, interior design, architecture which is more than dozen courses.

Internationally renowned designer + celebrity + famous enterprises tutor

Business celebrity as the Adjunct Professors, like Youngor Group President and Shanshan Group President.Professor overseas and designers coming to college to make lectures, and participate in teaching undergraduate courses, such as, the famous French designer Emanuel - Enge Luo (Emanuel Ungaro), the famous Italian designer Missoni (Missoni) and so on. Domestic wellknown professors such as Professor Zhang Wenbin, and Professor Yang Yixiong.

International and community-based

Working with Italian and European Institute of Design to establish close cooperation a dozen well-known institutions aboard. The college tries to expand contacts and cooperation of schools and enterprises, universities and research institutes, among intercollegiate, still between universities and government departments. While, establishment of teaching and research practice base on campus. Also hosting Shanghai international Fashion Culture Festival and international fashion Forum.

Transforming from applied Teaching type to research studio

To break through the limitations of existing teaching model, and to cultivate students' free creative ability, the Academy is being changed from the application of teaching-oriented model to study studio teaching methods, to provide students with real work environment.

Bureaucracy

The school teaching management organization has four parts, that is, the Party organizations, administrations and mass organizations, implementing a unified management under the leadership of the party secretary and the principal. 
From the main features of the creative fashion design talents training and domestic Donghua University and Edinburgh University, the main differences are from the educational idea, teaching methods and curriculum provision.

The first difference: education idea

The educational philosophy of the creative fashion talents training of Edinburgh University focuses on detail, emphasis on process and student-centered, focusing on people-centered emotional design, so as to nurture students' individual creative thinking and tap the potential of students and think for students career and career development. Donghua University from the big side effect,highlights the talents of the output, cultivating innovative talents with international vision.

The second difference: teaching methods

Edinburgh College of Art and Design in cultivating creative design talent takes the teaching model of the studio system. Instructors teach with short time, and the most important thing is to promote high-frequency contact of instructors and students, concern about the students and guide students to freely innovate. In addition, the key is the creation of the students having their own room, to give students greater time and space of freedom and creation. Donghua University is currently transmit into the studio teaching model, while restructuring the system, but the majority time for class, students are lack of time for freely creation.

The third difference: curriculum provision

Creative fashion design talents training of the University of Edinburgh in the majors basically covers all segments of today's fashion world.and freely choice for students. while focusing on college interdisciplinary cooperation and exchanges, such as collaboration of fashion design and other non-apparel product design. Garment majority of Donghua University, although relatively abundant courses, but relatively not all-inclusive than the University of Edinburgh. The science and engineering courses opened, such as physics, inorganic chemistry, electrical and electronic technology, the students are lack of interest.

\section{Conclusion}

Difference factors affecting domestic and foreign creative costume design personnel training are many. In terms of higher education they can be divided into three parts,including higher education resources, education and cultural ideas, students themselves. Based on the core characteristics of creative fashion design talent cultivation of University of Edinburgh and Donghua University, the differences between the two are mainly educational philosophy, teaching methods and curriculum provision. Edinburgh University has a world-class art and design, worth learning and reference for domestic higher institutions.
Although Donghua University was the establish cooperative relations with the University of Edinburgh, the key is to combine their own characteristics, and selectively introduce advanced experience of foreign countries. Other domestic universities in selecting creative fashion design talent training mode, should not blindly copy, and completely introduce foreign advanced concept, but requires a combination of practice and universities themselves. Through improving higher education resources, education and cultural ideas, walk out of a road of creative fashion design talents cultivation with Chinese characteristics, and more the school's own characteristics. Of course, there are also shortcomings in this paper, for example, the number of questionnaire survey is slightly less, and the part of the comparative analysis could increase the object of the contrast, so as to improve the accuracy of the results. All of this in a follow-up study can be improved.

\section{References}

[1] Shi Mei. Innovative talents training of International Perspective [J] .Journal of Huainan Normal University, 2008,8 (6): 104-106

[2] Li Wenli, Wei Xin .The comparison of Chinese and foreign appropriation of higher education and the reform trend of the allocation system of Chinese higher education institutions [J] .Education Economy .1997 (12): 34-38.

[3] Zhang Chao, Zhou Zenghuan. Factors of creative talents training from Chinese and foreign education ecosystem contrast [J] .Journal of Chinese Medical Education .2012,11 (5): $460-462$.

[4] Peng Xujuan. Foreign innovative talent training model and inspiration $[\mathrm{J}]$ Liaoning Journal of Higher Vocational Education .2007,9 (6): 18-19.

[5] Li Hongqin. clothing creative design emotions reflect [J] Wuhan University of Science. 2005 (18), 12: 1-2.

[6] Xu Qiujie.shall be clean autumn innovative spirit and practical ability for training - clothing creative design - curriculum system reform [J] Zhejiang University of Technology .2012,29 (3): $459-460$.

[7] Li Aimin. Analysis about cultivation of clothing creative design [J] ZHONGGUOTIWEIYIJIAOYU.2011:54-55.

[8] Gao Xuelian.High lotus enlightenment abroad innovative training model of reform in higher education [J] .Higher Agricultural Education. 2007 (1): 85-87.

[9] Peng Hongying.Comparative Study of Chinese and American creative industry development[D].Master degree thesis of Huazhong Normal University.2008.

[10] Yu Yiqing,Ling Ni.Thinking and Exploration of Chinese highlevel creative design talent cultivation under an international Perspective[J].Modern decoration.2011(9): 57-58. 